\title{
An Application of the Role-Value Distinction in Mental Space Theory to the Analysis of Definite and Indefinite Noun Phrases
}

\author{
HeLLe DAM-JENSEN \\ Institut for Sprog og Erhvervskommunikation, Handelshøjskolen, Århus, \\ Danmark
}

\begin{abstract}
Fauconnier (1994) foreslår en beskrivelse af fortolkningen af bestemte og ubestemte nominalsyntagmer. Formålet med denne artikel er at forklare hvordan Fauconnier's rolle-/værdidistinktion kan integreres i denne beskrivelse således at den på en ensartet og generel måde kan forklare fortolkningen af nominalsyntagmer indledt af henholdsvis den bestemte og ubestemte artikel i spansk.
\end{abstract}

\section{INTRODUCTION}

Traditional truth-conditional semantics takes as a starting point that the grammatical category ' $\mathrm{NP}$ ' describes individuals. This view, however, may be questioned, for example with appeal to data such as the following:

(1) El abrigo que has comprado también se puede comprar en Barcelona.

'The coat that you have bought can also be bought in Barcelona.'

The NP, el abrigo que has comprado, provides information for conceptualising a specific coat belonging to a particular person, and subsequently for conceptualising a model of that coat; that is, one and the same NP creates a conceptualisation of both an individual and of a kind. Such cases of reference cannot be explained by frameworks which take as a starting point that there is a one-to-one relationship between language and the world. I shall argue that the distinction between roles and values developed by Fauconnier in the framework of mental space theory is capable of handling problems of reference such as this. Roles and values are interpretations established on the basis of linguistic Tidsskrift for Sprogforskning • Årgang 4 • Nr. 1-2 • 2006, pp. 245-273 
HeLle DAM-Jensen

expressions combined with information from context and background knowledge. On the assumption that the distinction between roles and values is fundamental to our conception of entities in general, I shall argue that it is basic to the interpretation of linguistic expressions which describe entities. Fauconnier (1994) provides a framework for the interpretation of definite and indefinite NPs. It is the aim of this paper to examine how it corresponds with an interpretation of NPs introduced by the definite and the indefinite article in terms of the distinction between roles and values when applied to data in Spanish.

\section{KINDS AND INDIVIDUALS}

'Roles' and 'values' may be compared with the distinction between kinds and individuals. This distinction is an object of study both in the fields of linguistics and philosophy. It is characteristic of work in these fields that 'kind' and 'individual' are employed both of the meaning or reference of linguistic expressions and of the linguistic expressions themselves.

In this paper, I shall set out by comparing different pioneer studies from the fields of linguistics and philosophy of the distinction between kinds and individuals. The different conceptions of the distinction may be explained with reference to the semiotic triangle (Ogden/Richards 1923: 11) as sketched below: 


\section{Thought or reference}

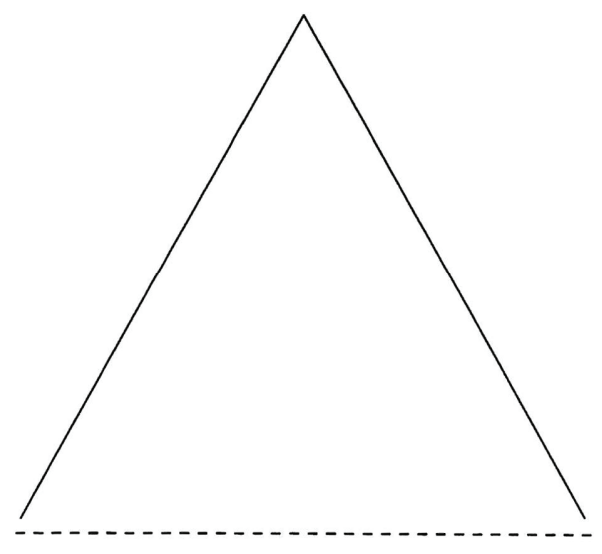

\section{Symbol}

\section{Referent}

Figure 1

Translating the concepts of 'kind' and 'individual' into the terms of this triangle, we shall say that the distinction applies to either the level of symbol, the level of thought or to the level of referent.

If we go back to the Aristotelian study of categories, it is the relation mediating between thought and referent which is the centre of study. Although language is a cornerstone in Aristotle's conception of categories in the sense that reality is assumed to provide a set of fundamental categories which, in turn, provides language with a fixed meaning, the meaning of specific linguistic expressions is not an object of study. The distinction between kinds and individuals is subsumed by the category of substance and is consequently ascribable to the level of thought. Substance is a hierarchy of different kinds of substances, divided into primary and secondary substances. Primary substances are characterised as being basic to existence and as being clearly independent, unlike secondary substances which are only indirectly so. It is furthermore characteristic of primary substances that they are found at the lowest level of the hierarchy, and that they are constituted by individuals. Secondary substances subsume species and genera ${ }^{1}$.

Later philosophers, such as Frege, also presuppose a direct relation between language and reality although Frege's distinction between sense and reference 
HeLle DAM-Jensen

shows that this relation is more complex than recognised in Aristotle's studies. A consequence of Frege's "realistic approach" to the relationship between language and world is that he does not recognise the mind, or thought in the terms of the semiotic triangle, as an explanation of how linguistic expressions come to have meaning, or sense. In Frege's view, senses are not mental, but they do not belong to the physical world neither. Rather, they belong to the so-called third realm. Dummett (1991: 250-252) points out that this view has as a consequence that it is not possible to explain how senses are attached to linguistic expressions. In the words of Dummett (1991: 251): "as long as this perspective is dominant, all is mysterious". As opposed to Aristotle, who studied language as a way of studying reality, Frege studied language with the aim of defining it in terms of truth conditions specified in logical representations, the predicate calculus. Therefore, the equivalent of the distinction between kinds and individuals applies to linguistic expressions; that is, symbol rather than thought. This notation employs variables and constants to represent arbitrary elements of a set and elements with a fixed denotation, respectively.

As is evident, being mere representations, these terms have nothing to say about the criteria for determining what it means for something to be a variable or a constant; that is, how one should define the necessary conditions for establishing whether a linguistic expression is to be conceived of as either an individual or as a kind. This, on the contrary, is a central point in Donnellan's (1966) account of the use and denotation of definite descriptions. Where the distinction between constants and variables is used to provide representations, the aim of Donnellan's study is to explain different uses of definite descriptions in particular.

The point of interest in Donnellan's study is to outline the use of definite descriptions in terms of a set of notions comparable to 'kind' and 'individual'. Donnellan's contribution to the discussion of how to understand entities on the basis of definite descriptions was intended as a criticism of Russel and Strawson. He argued that both Russel and Strawson, due to the lack of appeal to context in their accounts of definite descriptions, failed to explain important matters of reference. According to Donnellan, definite descriptions may be ambiguous between referential and attributive uses; that is, definite descriptions may be used either referentially, as referring to someone/something in particular thus 


\section{an Application of the Role-Value Distinction in Mental Space Theory to the Analysis of DeFINITE AND INDEFINITE NOUN PHRASES}

enabling the hearer to pick out that someone/something, or attributively, as asserting something about whatever or whoever. In Donnellan's view, this shows that extra-linguistic context is needed to decide the meaning of definite descriptions. Since one linguistic expression may have two distinct uses, the distinction between kinds and individuals as recognised in Donnellan's study, must apply to thought, as opposed to Frege, as well as to Russell, rather than to linguistic expressions although he does not explicitly say so. It is then the relation between symbol and thought which is the centre of interest.

As anticipated above, the distinction between referential and attributive uses was merely meant to account for problems of reference applying to definite descriptions. Indefinite descriptions, on the contrary, are usually accounted for with a starting point in the notion of specificity. The distinction between specific and non-specific interpretations, in modern times, originates from Baker (1973). According to Baker, the non-specific interpretation applies to indefinite NPs which do not refer to any particular object. This is why such NPs cannot be paraphrased by "a certain". NPs with a specific reading, on the other hand, allow this paraphrase. If we attempt to fit the description in the semiotic triangle, it seems that it is ascribable to thought since specific and non-specific are described as interpretations. Finally, yet a different understanding of 'kind' should be mentioned; this is generic reference, which makes 'kind' even more complicated to handle.

A common point of the distinction between specificity and nonspecificity and that of attributive/referential uses it that they are employed to account for different ways of conceiving a particular NP type. Both definite and indefinite NPs may be considered as referring to things conceived as either kinds or individuals. The way in which reference to kinds or individuals is established, however, differs depending on NP type. On this line of argument, I shall claim that kinds and individuals are understood in different ways depending on whether information is provided by definite or indefinite NPs. As a consequence, a more precise and fine-grained explanation of what it means for the two types of NPs to allow for the two interpretations is needed. This point is elaborated in section 5.1. 
Summing up, we may say that the different approaches described so far differ in their use of 'kind' and 'individual'. Whereas the Aristotelian study of categories defines substance in relation to reality, Frege utilises constants and variables to represent linguistic expressions depending on the way in which they refer to things in the world. To assume a direct relation between language and reality, however, is problematic in several respects. In many cases we talk about things which do not exist, and often language is used figuratively. Moreover, one and the same linguistic expression may be used with more than one meaning, as manifested for example in the studies of Donnellan and Baker. As a result, it seems dubious to locate the distinction at the level of symbol. Instead, I shall argue that it should be located at the level of thought. Thought, in this work, should be understood as interpretation; that is, as interpretation of linguistic expressions. So what should be the focus point in a characterisation of 'kind' and 'individual' is the relation between symbol and thought. On this view, 'kind' and 'individual' are to be understood as interpretations created in the mind of speakers on the basis of information from NPs and their context. This again generates a need for a more detailed explanation of 'thought'. Theories of the content-side of language usually make a distinction between meaning and reference although the basis on which the distinction rests differs from one theorist to another (Lyons 1977: 174-176). In modern linguistics, meaning is usually taken to apply to linguistic expressions (although there is no consensus as to the exact way in which it applies), whereas reference is a relation created by language users in an interpretive process. I shall not go into details with respect to how meaning is constructed, but merely assume that the establishment of meaning is the basis for creating reference. I shall define reference as the result of an interpretive process performed by language users on the basis of information from linguistic expressions. On this view, I shall assume that 'kind' and 'individual' are relations established on the basis of information from linguistic expressions, and that they therefore belong to reference.

At this point, one may ask what we may learn about the nature of the relation between thought, symbol and referent from the triangle itself and its theoretical basis. According to Ogden/Richards (1923: 11), we establish reference on the basis of linguistic expressions. As reference is equalled with thought, there is reason to believe that this view on reference to some extent coincides with my view as formulated above. In this connection it is worth noticing that the 
an Application of the Role-Value Distinction in Mental Space Theory to the Analysis of DeFINITE AND INDEFINITE NOUN PHRASES

relation between symbol and referent is only indirect; in the words of Ogden/Richards (1923: 11) it is "an imputed relation". This is represented in figure 1 as a dotted line. On this basis, a parallel may be drawn to the conception of this relationship advocated for by cognitive frameworks. Fauconnier (1997: 36) illustrates it as follows:

$\begin{array}{lll}\text { E } & \mathrm{C} & \mathrm{R} \\ \text { Language } & \text { Construction at } & \text { Real or metaphysical } \\ \text { expressions } & \text { level C } & \text { world }\end{array}$

Figure 2

However, where Ogden/Richards refrain from accounting for the exact nature of the relation between symbol and referent, Fauconnier's illustration clearly reflects the status of the world relative to language. Linguistic expressions are not linked to objects in the world. Reference is therefore not established with a starting point in the objects in the world to which linguistic expressions traditionally are taken to refer. On the contrary, language is taken to prompt clues for an interpretive process which may or may not, reflect objects in the world. That the world forms an important part of the basis on which we interpret linguistic expressions, is a different matter.

I shall argue that a framework is needed which is capable of making these assumptions explicit, and furthermore that the theory of mental spaces provides such a framework. The concern of the subsequent section is to substantiate this claim. As anticipated above, the notions of kind and individual are translated into 'role' and 'value' in that framework.

\section{COGNITIVE SEMANTICS IN GENERAL - THE THEORY OF MENTAL SPACES IN PARTICULAR}

As opposed to truth-conditional semantics, the area of cognitive semantics, in general, regards meaning as being constructed individually by language speakers in an interpretive process on the basis of information from language, context and background knowledge. This view on language allows us to account for aspects of meaning which cannot be accounted for in the realm of truthconditional semantics. Firstly, assuming that meaning is established mentally facilitates the explanation of the meaning of linguistic expressions which do not 
follow the principle of compositionality. This applies for example to all types of idiomatic expressions. Moreover, a mental view on language takes into account that the way we understand linguistic expressions may differ depending on the depth of our knowledge of their conceptual content; that is, that the amount of information with which concepts are packed varies from one person to another (Thrane 1997: 243-245). Secondly, the introduction of context as a parameter in the establishment of meaning makes it possible to account for linguistic expressions the meaning of which is undecidable if taken in isolation. Lastly, as stated above, it is a basic assumption of a cognitive framework that an account of meaning should be procedural. The consequence of this is that focus is on the process leading to the establishment of meaning, rather than merely on the result itself. This allows us to give a detailed explanation of the different factors which contribute to the establishment of meaning.

On the basis of this view of language, different theoretical frameworks have developed. An outstanding example is Langacker's Cognitive Grammar (Langacker 1987; 1991). This framework aims at providing a cognitively founded explanation of linguistic organisation which, unlike truth-conditional semantics, includes figurative language as an essential part of linguistic analysis (Langacker 1987: 1). Within this setting, it aims to provide a precise definition of basic concepts in linguistics, such as word classes, grammatical functions and relations. A different pioneer in the field is Leonard Talmy, who, like Langacker, aims at providing an outline of the way in which conceptual structure is structured linguistically (Talmy 2000, 1/2). This work includes an investigation into different aspects of event structure in which the semantic notion of force dynamics is applied. Force dynamics generalises over different types of expressions of "causing" which include, not only physical causing, but also structures which create psychological causing.

Like Langacker, Fauconnier (1994: 1) takes figurative uses of language to be central to semantics. The aim of mental spaces was originally to provide a framework which was capable of accounting for semantic problems which could not be explained by traditional formal theories of meaning. Apart from figurative language, this applies among others to expressions which do not stand in a one-to-one relationship with objects or situations in the world, such as NPs which establish fictitious beings such as witches and hobbits. To this one may 
add sentences corresponding to Jackendoff's famous example: In this painting, the girl with the brown eyes has green eyes. In the scope of mental space theory, the explanation of such expressions is handled by letting reference work between mental spaces, rather than between linguistic expressions and the world (see section 5). Apart from these ontological problems of reference, also problems of reference attaching to definite NPs in particular called for a theoretical framework capable of providing a unified explanation of their semantics. Typical problems are referential opacity and scope dependencies. It is the interpretation of such phenomena among others that mental spaces model. Although mental space theory focuses on diverse problems pertaining to linguistic analysis in general, an account of the way in which we conceive entities may be considered a focus point, both due to the introduction of the distinction between roles and values and to its account of the distinction between definite and indefinite NPs. On this view, I shall consider it an operative frame for the analysis offered in this study.

Before providing an explanation of the interpretation of NPs, attention should be drawn to an important insight which Fauconnier makes in his introductory note to Mental spaces (1994: 1): "Relatively simple grammatical structures give instructions for space construction in context". Put into different terms, this means that it is a property of grammatical items in particular that they carry instructions for the structuring of the interpretive process. Carrying this view a little further, we shall say that grammatical items tell us how to interpret lexical items. This is a cognitive reinterpretation of the classical distinction between grammatical and lexical meaning. I shall argue that making this distinction allows us to give a precise account of the interaction between categorically different linguistic expressions in the interpretive process. This is a view which is supported by Talmy (2000: 21-24), but which according to Langacker (1987: 3) is not productive.

\subsection{A discussion of recent developments of mental space theory}

The application of the role/value distinction in this study is based on Fauconnier's 1994 work in particular. Since then however, Fauconnier has developed the framework of mental spaces in collaboration first and foremost with Mark Turner (see for example Fauconnier/Turner 1998 and 2002). An important part of this development is blending theory. In this framework, 
mental spaces serve as input spaces to a different space in which new conceptual structure emerges as a blend of the information provided by the input spaces. Blending was originally developed to give a more precise and fine-grained explanation of the conceptualisation of metaphors (Coulson 2001: 165-166), but from there it developed into a tool for explaining other conceptual relations, such as for example analogical counterfactuals and modified noun phrases (Coulson 2001).

As opposed to mental space theory, which aims at explaining meaning created on the basis of linguistic expressions, blending aims at explaining cognitive activity in general. This is a consequence of the view that language operates at a level equal to other types of sense impressions in revealing human cognition. It seems to me, though, that there are important differences between language and other types of sense impressions which blending theory is too general to capture. In an attempt to explain the relationship between syntax and meaning, Thrane (2004) elaborates on ideas about information proposed by Dretske (1981)/(1995). Dretske makes a fundamental distinction between two types of representation systems: natural systems and conventional systems. It is this division which is Thrane's starting point for substantiating the assumption that language differs radically from other types of representation systems. In virtue of being symbolic, language belongs within Dretske's conventional representation system. This implies that it is designed to inform about something different from itself; by being conventional, it allows us to decode it on the basis of a set of more or less fixed rules. The information that we receive from language is then combined with information from other types of sense impressions (Thrane 2004: 44). I shall argue that keeping these sources of information apart enables us to account in a precise way for the specific way in which different types of information contribute to the interpretive process, in virtue of the type of representational system to which they belong. And the other way round: I shall argue that generalising over sensory inputs prevents us from giving a precise analysis of the way in which meaning is established on the basis of linguistic expressions.

In conclusion, in the theory of blending, Fauconnier/Turner provides a means for explaining the process of understanding in general. But, having said that, if we want to give a precise explanation of the process of understanding of 
language, it is imperative to make a clear division between the interpretive impact of language and that of other types of sensory input. Secondly, an explanation of the interpretive effect of the interaction of different types of linguistic items should be given.

\section{THE THEORY OF MENTAL SPACES: ROLES AND VALUES DEFINED}

It is a central aim of Fauconnier's theory of mental spaces (Fauconnier 1994, Fauconnier/Sweetser 1996) to account for the way in which speakers establish cognitive links between mental representations created on the basis of linguistic information and information from context. In general terms, language provides information for creating mental spaces, mental objects, called elements, in such spaces, and connections between them. Inspired by Nunberg (1978), Fauconnier uses the Identification (ID) Principle to account for our ability to create such cognitive connections between elements. One type of connection is role/value relations. The connection between roles and values accounts for our fundamental conception of elements. An element may either be understood as pointing to no particular individual, a role, or it may be understood as pointing to a particular individual, a value. If something is conceived as not pointing to any particular individual, it merely describes the properties which are essential for being some thing - that is, a matrix of essential properties. Values, on the other hand, are characterised as having a fixed identity; they are located in time and space. It is important to note that elements are not given in virtue of correspondence with the real world. Seeing that elements are mental phenomena, it is without importance whether the items such elements describe have existence in the real world or not. So, if individuals of a kind cease to exist in the world, one is still able to conceive of such individuals.

Since elements are mental objects (cf. Kartunnen's (1976) notion of discourse referent) made individually in the mind of speakers on the basis of information, also the properties making up such elements must be created individually in the mind of speakers. However, in order for an act of communication to be successful, there must be points of correspondence in the way we conceptualise such elements. If we think of lexical meaning in terms of types and tokens, we shall say that lexical meaning may be thought of as types and tokens, in the sense that tokens belong to individuals, whereas types are public: "The lexical meaning of a noun must be the meaning of the public noun type. It is therefore 
an abstraction, obtained from the generalized, transformed and reduced information carried by all the tokens of that type" (Thrane 1997: 246). In this sense, the meaning of words is interconnected through the public word type. So when we speak of essential properties of the meaning of words, they should be thought of as constituting a generalisation of all individual uses of the word to which they are linked.

Returning now to the notions of role and value as a means for explaining our conception of elements, it is noticeable that, although they in several ways are similar to the distinctions between specific/non-specific and referential/attributive uses, they differ in important ways. First of all, 'roles' and 'values' are generalisations not particular to specific NP types. Secondly, they are not two distinct readings; rather, they are interlinked in the sense that the role underlies the value. This means that whenever we conceive of an element, it is conceived of as a role which then, if information is provided, may be satisfied by a value. Information for establishing one or the other reading is provided by context. It is not possible to provide an exhaustive list of types of information contributing to one or the other reading, but it is fundamental to value readings that information must be provided to establish time and space. These facts are made explicit in the following general notations (Fauconnier 1994: 41):
A. $\quad \mathrm{P}(\mathrm{r})$ : property of a role
B. $\quad \mathrm{P}(\mathrm{r}(\mathrm{m}))$ : property of a value of a role

$\mathrm{P}$, in these notations, is unspecified for subject; it is an open predication. A shows the role reading and $\mathrm{B}$ the value reading. They may be explained with reference to examples (2) and (3):

(2) En cine y televisión el actor depende de más factores que en el teatro.

'In film and television, the actor depends on more factors than in theatre.'

(3) La policía detiene en Cataluña a 16 presuntos miembros de Al Qaeda. Los agentes requisaron material electrónico y bidones con productos químicos.

'The police arrests in Catalonia 16 presumed members of Al Qaeda. The policemen confiscated electronic equipment and containers with chemical products.' 
If $\mathrm{A}$ is applied to example (2) above, $\mathrm{P}$ represents the predication depende de más factores. This property is applied to the element introduced into a mental space by the subject NP, el actor. Information is not provided for locating this element in time and space, it therefore has a role reading. B is distinguished from A by integrating a parameter, $m$, for context. If applied to (3), the element set up in a mental space by the subject NP, la policía, is first interpreted as a role, $r$. The value reading is then a result of applying context to the reading of this element; of the application of the contextual parameter, $m$ to $r$. The context which establish time and space is tense and the prepositional phrase, en Cataluña.

These notations make explicit that the interpretation of NPs is dependent on context through the contextual parameter, $m$, in B. Secondly, they represent the role as underlying the value. Unlike the predicate calculus, the framework of mental space theory is dynamic in that it represents the process of interpretation, rather than the result of interpretation.

The account of role/value relations given above is based on the description provided by Fauconnier (1994). But just as the whole theoretical framework of mental space theory is reassessed in later work of Fauconnier and Turner, also the role/value distinction is explained from a somewhat different angle. For blending to take place, a set of basic principles are presupposed. These principles are called vital relations. Fauconnier/Turner (2002: 89-106) establish a typology of such essential conceptual relations which we establish in mental processing. Role/value relations are considered to be a vital relation. The consequence of this assumption is that the distinction no longer is dependent on the reading of particular instances of linguistic expressions; that is, roles and values are not (only) considered to be interpretive results stemming from linguistic expressions. Instead they are employed as designations for what may be called a conceptual network of hyponymy relations. Fauconnier/Turner (2002: 98) give as an example the relation mediating between head of state, president and Lincoln. President is a value of head of state, but at the same time it is the role of Lincoln. Fauconnier/Turner do not go into details with respect to the theoretical consequences of the assumption that what is understood as a value of a role at one level, may be understood as a role of a different value at another level, nor 
do they specify the advantages of the approach in comparison to first order logics.

In conclusion, if we assume that the role/value distinction forms an essential part of our conception of elements, it is basic to the interpretation of linguistic expressions which introduce elements into mental spaces. It is the purpose of the next section to explain how the role/value connection may be integrated in an analysis of NPs.

\section{Application of the ROLE/VALUe CONNECTION to the ANALYSIS OF NPS}

Fauconnier (1994: 146) states that one way in which context may provide information for creating a link between a role and a value is grammatically by the verb "be". He gives among others the following example²:

(4) If Mary was the queen of England, everything would be fine.

In this example, be provides information for creating a pragmatic connection between a role and a value. Mary identifies a value, and the queen of England sets up a role. According to Fauconnier (1994: 146), this is a link within a space. It may be illustrated as in figure 3 :

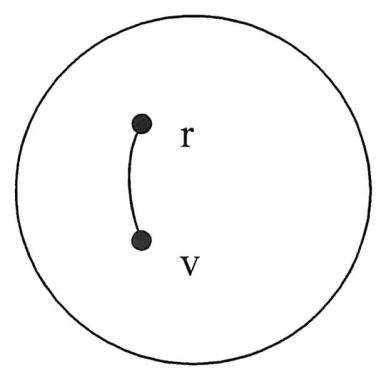

$\mathrm{M}$ r: the queen of England

v: Mary

Figure 3

However, the case may be more complicated since the subject NP also allows a value reading if the "if"-clause is put into a different context. The following contextualisation brings out the value interpretation (Fauconnier 1994: 147): 
an Application of the Role-Value Distinction in Mental Space Theory to the Analysis of DeFINITE AND INDEFINITE NOUN PHRASES

(5) If Mary was the queen of England, she would have a sister, Margaret, and a son, Charles.

According to Fauconnier, the NP the queen of England points to a role which identifies a value, $a^{\prime}$, in a space, $H$, set up by the hypothetical construction introduced by if. The proper noun, Mary, on the other hand, identifies $a$, in reality space, $\mathrm{R}$. When a connector, $f$, is applied to $a$ in $\mathrm{R}, a^{\prime}$ is the value of the function, $f(a)$. In this case, the verb be establishes a connection across spaces. The appropriate space illustration may look as follows:

a: Mary

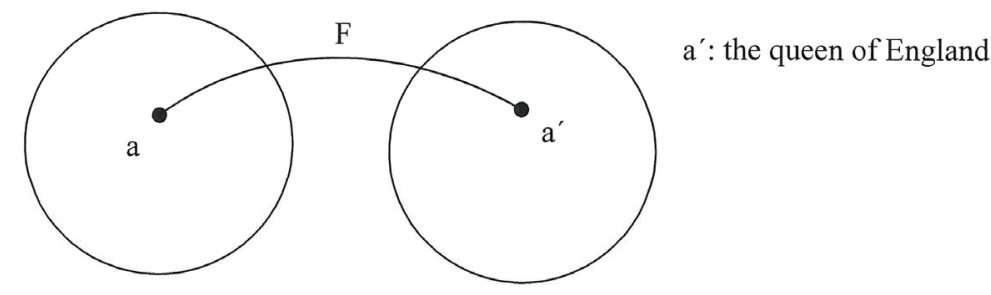

$\mathrm{R}$

$\mathrm{H}$

Figure 4

The difference between the illustrations of (4) and (5) lies in the link established by be. In (4) it results in forming a link within one and the same space. In (5), on the other hand, the situation is somewhat more complicated. Be gives information for creating a role/value relation between the elements set up by Mary and the queen of England. These elements are then linked in a relation across spaces in which one of them is hypothesised to be identical to the other. In general, it seems then that connections between roles and values may be established either across or within a space. However, I shall make the claim that role/value mappings always are established within a single space on the assumption that this will provide a uniform account of elements in spaces. Before developing this point, I shall outline Fauconnier's characteristics of definite and indefinite NPs, in particular.

5.1. The relation between role/value connections and the interpretation of definite and indefinite NPs

Fauconnier (1994: 20) describes the reading of definite NPs in the following way: 
The noun phrase the $N$ in a linguistic expression points to an element $a$ already in some space $\mathrm{M}$, such that "N"(a) holds in that space.

What this characteristic says is that definite NPs identify elements in mental spaces which are already set up. The characteristic of indefinite descriptions, on the other hand, goes as follows:

The noun phrase $a N$ in a linguistic expression sets up a new element $w$ in some space, such that " $\mathrm{N}$ " $(w)$ holds in that space. (Fauconnier 1994: 20)

This amounts to saying that the difference between definite and indefinite descriptions resides in the way elements set up in a mental space.

According to Fauconnier, these characteristics are not complete as they only explain value readings. To this I shall add that they need refinement in order to provide a general and uniform characteristic of the interpretation of the two NP types. I shall propose that the integration of the role/value distinction into the general characteristics of the reading of definite and indefinite NPs will take these points into account. First of all, it will make explicit that the ability to generate either a role or a value reading is a general property of NPs. Secondly, it will make the framework more fine-grained so that, on the one hand, it may account for interpretive differences between definite and indefinite NPs, in a general way. On the other hand it may account for more subtle case of reference established on the basis of each NP type.

\section{REFORMULATION OF THE CHARACTERISTIC OF THE INTERPRETATION OF DEFINITE AND INDEFINITE NPS}

Seeing that the role always underlies the value, it must necessarily be so that whenever an element is set up in a space, it should be conceptualised as a pair constituted by a role and a value (Dam 2001: 101-102), as illustrated below: 


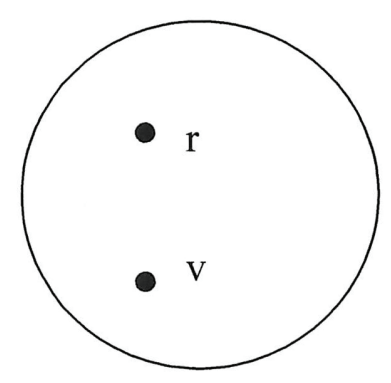

M

Figure 5

If context provides information for applying the value to the role, $v$ is attributed to $r$ as shown in figure 6:

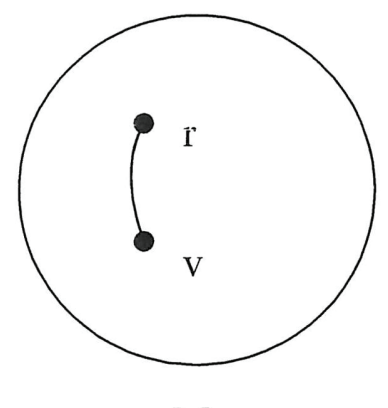

$\mathrm{M}$

Figure 6

Figures 5 and 6 are then assumed to be two general representations of interpretations of elements in spaces. Regardless of how such elements are introduced into a space, they are always conceived of as a pair. The following explores how this may be integrated into the characteristic of definite and indefinite NPs.

I shall start out by explaining the role and the value reading of indefinite NPs in Spanish with a starting point in examples (6) and (7) below.

(6) Yo sólo quise hacer una película en la que salieran unos rojos más divertidos de lo que acostumbraba a ver, [...]

'All I wanted to do was make a film in which some reds which were funnier than what I was/(s)he was used to see should appear, [...]' 
Todas las habitaciones tienen una cocina bien equipada.

'All the rooms have a well equipped kitchen.'

In Spanish, attributive relative clauses of which the VP appears in the indicative as a rule are taken to generate a specific reading of the entity created by an indefinite NP, whereas only the non-specific reading is available if the subjunctive is used. On this basis, the fact that the VP of the attributive relative clause of example (6) appears in the subjunctive makes a non-specific and not a specific reading available ${ }^{3}$. It is characteristic of the non-specific reading that it merely describes the properties which are essential to being something, in this case something which matches the description of [PELICULA] with the property described in the relative clause. The non-specific reading is therefore subsumed by the role reading. This implies that the pair of elements, $r$ and $v$, set up by the indefinite NP una película en la que salieran [...], is not connected in the following figure.

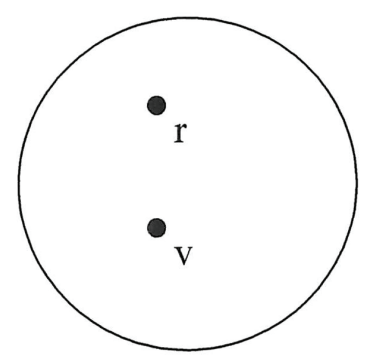

r: una película en la que salieran $[\ldots]$

M

Figure 7

Also in (7), a pair of elements, $r$ and $v$, are introduced into a mental space, M, by an indefinite NP, una cocina bien equipada. In this example, it is the lexicality of the head of the VP, tienen, which provides information for establishing the conceptualisation of the pair of elements set up. As the meaning of [TENER] implies that there is an object of which the subject has ownership, it is the specific reading which is available. In terms of this work, this corresponds to the value reading, which appears from the figure below in which $v$ is applied to $r$. 


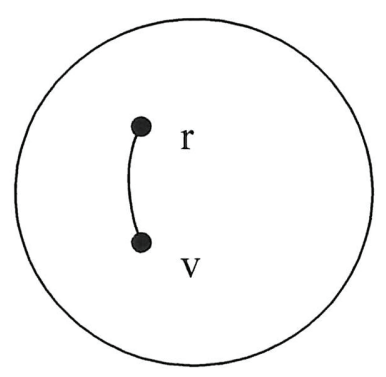

v: una cocina bien equipada

M

Figure 8

This configuration differs from Fauconnier's in assuming that the specific reading is a relation between a role and a value within a space. In Fauconnier's (1994: 26-27) configuration, the specific reading of indefinite NPs - that is, the value reading - is represented as a relation between two elements in two different spaces. The advantage of the representation in figure 8 is that it makes it possible to keep the illustration of the specific reading and that of the role reading of definite NPs apart as we shall see.

It appears to be the case that the reading of some indefinite NPs allows a more evident classification as roles or values than others. On the assumption that the role reading implies a description of a matrix of essential properties, rather than a fixed identity, (7) above is easily classified as generating a value reading, due to the lexicality of the head of the VP. The value reading of the following example may not appear to be quite as evident.

(8) Efectivamente, el otro día Martín Berasategui, que es mi actual asociado en la cocina de El Amparo, afirmaba que él lo debe todo a su madre y a una tía.

'Indeed, the other day, Martín Berasategui, who is my present colleague in the kitchen at El Amparo, said that he owes everything to his mother and to an aunt.'

This example does not contain elements which clearly promote one or the other reading of the indefinite NP, una tía; rather, it is the sentence as a whole which makes us conceptualise a situation in which the element created by the subject, él, has in fact an aunt. This is why the element set up by una tía has a value reading. 
Consider now the following pair of examples:

(9) Un macho tiene una personalidad más fuerte y es más difícil de educar mientras que una hembra es más tranquila y se deja dominar más.

'A male has a stronger personality and is more difficult to educate, whereas a female is quieter and lets herself be dominated more easily.'

(10) Un niño que no come, se distingue de un niño que no quiere comer en que el primero se enflaquece, pierde peso, en cambio el segundo [...]

' a child who does not eat, is distinguished from a child who does not want to eat in that the first becomes thin, looses weight, whereas the second $[\ldots]^{\prime}$

Apart from specific and non-specific interpretations, indefinite NPs are usually assumed to allow a generic interpretation. In (9), the fact that the indefinite NP appears in the subject position combined with the use of the simple present tense in the VP promotes a generic reading. The element created by the NP un macho does not point to any individual in particular, but to a matrix of essential properties of being 'a male'. It is to this matrix that the description provided by the predicate is assigned. In (10), the indefinite NP is combined with a relative clause in which the VP, come, appears in the indicative. As mentioned above, the appearance of the indicative mood in relative clauses generates a value reading, as a rule. However, as the VP in this example also appears in the present tense, we may be induced to establishing a role reading. This interferes with the information provided by the indicative. Therefore, if we want to be able to maintain the general meaning of the indicative, we need to explain what it means for un niño to create a value reading. Accordingly, we may imagine a situation in which a set of children are under medical examination, and it has been established that the property designed by the predicate, se distingue [...], applies to any member of that specific set of children ${ }^{4}$. Put into different words, the property designated by the predicate applies to any member of the set describable by un niño que no come. On this analysis, we may consider (10) a challenge to the characterisation of the value reading of indefinite NPs suggested above.

Before making further assumptions on the semantics of indefinite NPs, a brief comment should be made on genericness. According to standard semantic 
descriptions of the semantics of NPs, both the reading of definite and indefinite NPs may have a generic reading. Fauconnier/Turner (2000) attempt to formulate a more nuanced description of what it means for us to conceptualise a kind. To this end, they apply the notion of compression. Compression is a mental process in which parts of a relation are either left out (syncopation) or scaled down (scaling) with the effect that a complex situation is reduced to a single situation. Genericness is explained as a process of compression which implies a mental compression of all individuals in the type. "Their natures, experience and behaviours [are homogenized - HDJ] into a frame of prototypicality" (Fauconnier/Turner 2000: 300). Applied to the analysis of example (9) above, this means that the role reading of the element set up by un macho implies compression; all individuals describable by [MACHO] correspond to the property designated by the predicate tiene una personalidad más fuerte. This explanation of genericness first of all makes explicit that a role presupposes the existence of values. Next, it stipulates that such values correspond to the characteristics of that role. However, I find it hard to substantiate that the generic understanding of roles presupposes that values are reduced to a single object, in this case a role.

At this point, we may conclude that indefinite NPs are characterised as setting up a pair of elements in a space, $r$ and $v$, which, depending on context, may be connected. However, examples such as the following show that this characterisation needs refinement.

(11) Hace un mes, en el desierto de Mali, estuvo a punto de quedarse ciego de una picadura de escorpión en un ojo.

'A month ago, in the Mali desert, he was at the point of turning blind due to a bite of a scorpion in an eye.'

The context in which the indefinite NP, un ojo, appears, provides information for establishing a relation between the element set up by this NP and an element perceived as a person. It is our knowledge of the world which allows us to conclude that the element set up by un ojo is to be picked out from a pair. However, although we are not told which one in particular, the element set up in a space has a specific reading, a value reading; it is not any eye which is pointed to by un ojo, but a specific one which has suffered from a bite. If we want the characteristic of the interpretation of indefinite NPs to handle this use 
of the indefinite article, it needs further elaboration. In accordance with the assumption above, un ojo sets up a role and a value in a mental space, M. Then, in order to make explicit that the value of the role is picked out from a pair, we shall assume that a set of values, $\left\{\mathrm{v}_{1}, \mathrm{v}_{2}\right\}$, is introduced into $\mathrm{M}$, and that $r$ is connected to one of those, as shown in figure 9 below.

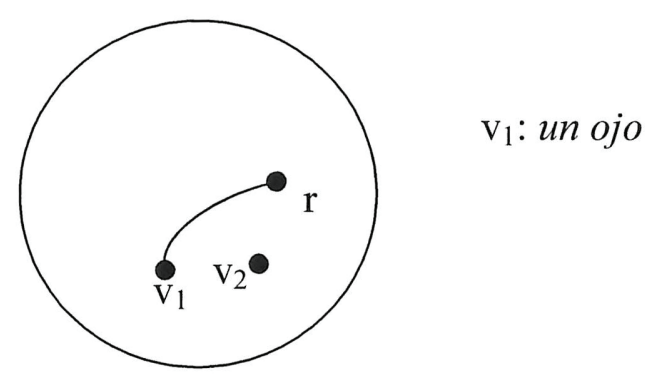

\section{M (estuvo a punto de quedarse)}

Figure 9

It is a precondition for this interpretation to be acceptable that it is based on a model theoretic approach. This approach also allows us to generalise over the characteristic of indefinite NPs by hypothesising that an element set up in a space by an indefinite NP always picks out an element from a set. This hypothesis corresponds to Hawkins' notion of exclusiveness used in his description of indefinite NPs in English (Hawkins 1978: 175-186).

The conception of indefinite NPs outlined above may be formalised in the following way:

The noun phrase $a N$ in a linguistic expression sets up a new set of elements, $r$ and $\left\{v_{1}, v_{2},[\ldots] v_{n}\right\}$, in a space, $\mathrm{M}$, such that "N" $r,\left(v_{x} \in\left\{v_{1}, v_{2}-v_{n}\right\}\right)$ holds in that space.

On the basis of this characteristic, a more fine-grained analysis of examples (6) and (7) may be provided in the following terms. In example (6), the indefinite $\mathrm{NP}$, una película en la que [...], introduces a role, $r$, and a set of values, $\left\{v_{1}, v_{2}-v_{n}\right\}$, in a space, $\mathrm{M}$, as illustrated in figure 10 below. As the element set up on the basis of the NP has a role reading, $r$ in $\mathrm{M}$ is not connected to any value from the set. 


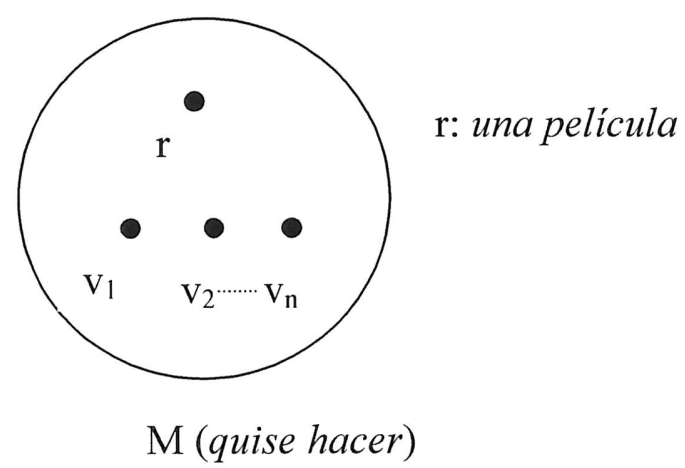

Figure 10

In example (7), the indefinite NP una cocina bien equipada also sets up a role, $r$, and a set of values, $\left\{v_{1}, v_{2}-v_{n}\right\}$, in a space, M. To render the value reading, $r$ is linked to a value, $v_{1}$, from the set. This is depicted in the following figure 11:

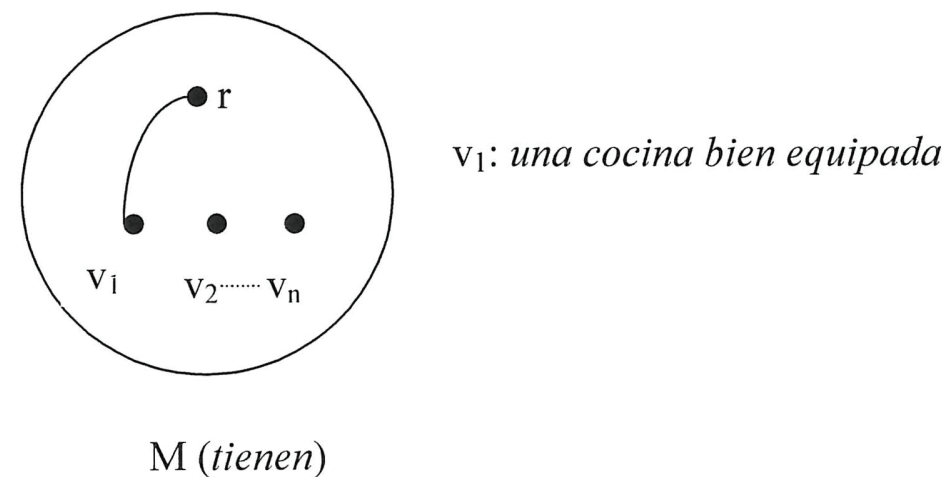

Figure 11

A further argument for maintaining that indefinite NPs pick out an element from a set, is that it is unusual to use indefinite NPs with an interpretation according to which the role set up has just one value; in (8), the subject is most naturally understood as having more than one aunt, otherwise a definite NP would seem more appropriate. This, however, does not follow logically, but must be an implicature of a model-theoretic approach to indefinite NPs.

The essence of the above is that the role reading is a broad notion, a generalisation, which comprises what otherwise may be regarded as different reference types. I shall claim that the advantage of applying the role/value distinction is that, by subsuming what is traditionally taken to be different 
reference types, it provides us with a means for explaining the meaning of NPs in a more general way.

With regard to definite NPs, we saw above that Fauconnier takes them to point out elements which are already set up in a space. It seems to me, though, that the result of this characteristic is that identification is supposed to take place between linguistic expressions and elements in spaces. However, seeing that it is a fundamental part of mental space theory as a cognitive theory that relations are established between elements in spaces, rather than between linguistic expressions ("[language - HDJ] builds up mental spaces, relations between them, and relations between elements within them" (Fauconnier 1994: 2)), it must necessarily be so that the process of identification works between elements in spaces, rather than between elements and linguistic expressions. I shall therefore assume that a characteristic of the interpretation of definite NPs should make explicit that definite NPs provide information for the hearer to set up elements in spaces which presuppose the existence of a different element to which it is connected.

As we saw in the discussion of indefinite NPs, the distinction between roles and values also applies to the interpretation of definite NPs. I shall suggest the following reformulation of Fauconnier's characterisation of definite descriptions:

The noun phrase the $N$ in a linguistic expression sets up a pair of elements, $r$ and $v$, in a mental space, $\mathrm{M}$, which presupposes the existence of a different set of elements, $r^{\prime}$ and $v^{\prime}$, in a different space, $\mathrm{P}$, such that " $\mathrm{N}$ " $(r, v)$ is asserted in that space.

It is uncontroversial to assume that the semantics of the definite article implies presupposition of some sort. The interpretation of linguistic expressions with logical implications, such as presupposition and entailment is characterised as generating the conceptualisation of a situation the existence of which is a logical necessity of the semantics of such expressions. In other words, the description of the interpretation of the definite article presupposes that there is an element to which an element set up by a definite NP may be linked. This means that an element set up in a space by the definite article logically presupposes the existence of a different element to which it may be linked. Since a mental space 
configuration is a graphic representation of meaning construction, it follows logically that such a presupposed element has existence in a space. This space is $\mathrm{P}$ (presupposition space) in the characteristic above. Such an element may be set up either explicitly by an indefinite NP occurring earlier in the text (although this does not appear to be the general case) or implicitly. The latter is the case in (2) and (3) above in which we infer such an element. On this basis, I shall explain the process of interpretation of the definite NPs of (2) and (3) in the following way:

In (2), the definite NP, el actor, introduces a set of elements, $r$ and $v$, in a space, M. The definite article then instructs us to conceive of a different pair of elements, $r^{\prime}$ and $v^{\prime}$, in another space, P. If information is provided for perceiving the element set up by el actor as an individual person, the role is attributed a value in both spaces. However, if such information is not provided, no connection is created, and it is $r$ and $r^{\prime}$ which are linked. A synthesis of the meaning of the context provides us with information for understanding the element set up by el actor, not as pointing to any person in particular, but merely to a role. As a result, it is $r$ and $r^{\prime}$ which are connected as depicted in the following figure.

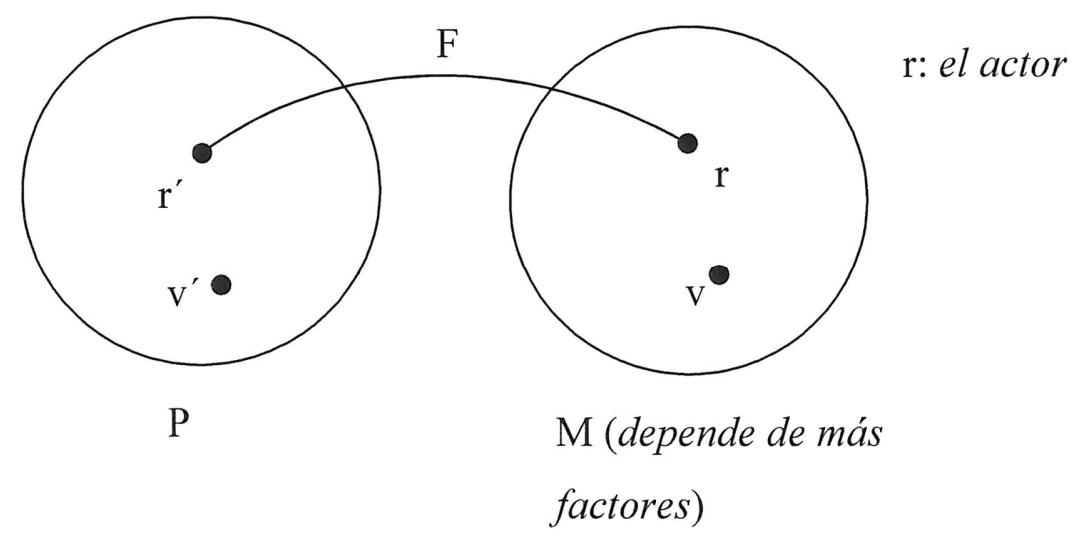

Figure 12

In (3), the VP, detiene, builds a space, M, into which the definite NP, la policía, sets up a pair of elements, $r$ and $v$, and a set of counterparts, $r^{\prime}$ and $v^{\prime}$ in a different space, $\mathrm{P}$. The context provides the information that the element set up by la policía performs an action at a specific place. Therefore we are to 
understand the element as a value. This is illustrated in figure 13 below as a role/value connection; $v$ and $v^{\prime}$ are connected.

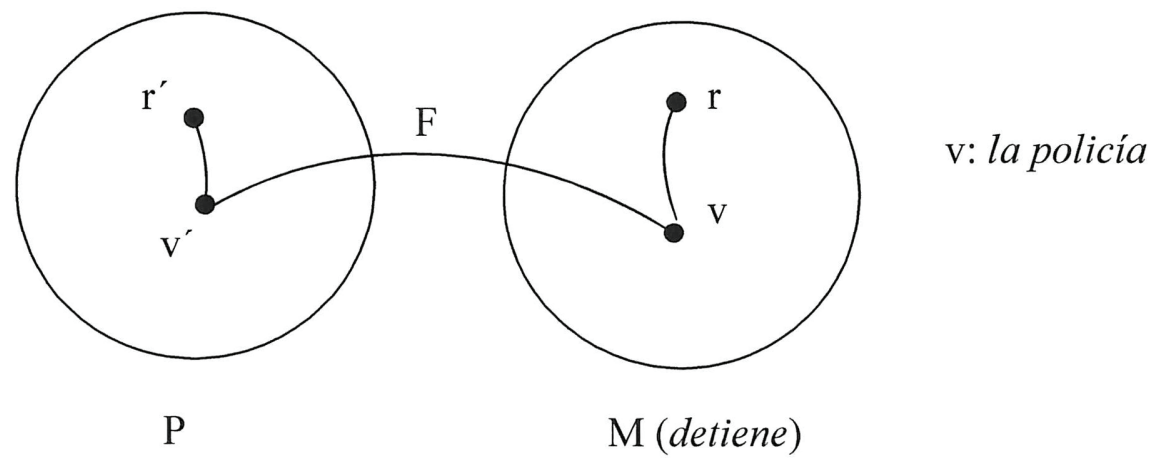

Figure 13

We may now explain the interpretation of (1) as a complex operation in which the NP, el abrigo que has comprado, is understood first as a value and then at a secondary level as a role. In this interpretation, the predicate, se puede comprar, builds a space, $\mathrm{M}$, in which the NP, el abrigo que has comprado, establishes a pair of elements, $r$ and $v$. The adjectival phrase, que has comprado, provides information for ascribing $v$ to $r$. However, the predicate se puede comprar instructs us to conceive the counterpart of the element in $\mathrm{M}$ as a role in a different space. This is why $r$ is connected to $r^{\prime}$ in figure 14 below:

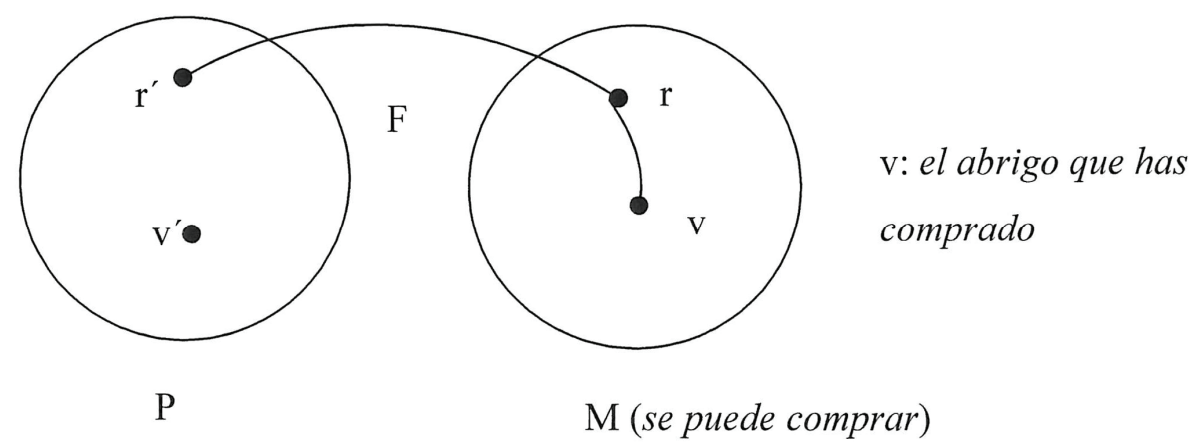

Figure 14

As we saw with respect to the interpretation of indefinite NPs, different interpretations of role and value readings may be reached depending on context. This implies that the role/value distinction subsumes such well-known distinctions as for example known vs. unknown, generic vs. particular, 
attributive vs. referential. These, as mentioned above, are merely different ways of perceiving roles and values.

\section{CONCLUDING REMARKS}

If we want a theory to have explanatory power, it should be as general as possible while still being as precise as possible. The analysis above should be seen as an attempt to provide such a theory of definite and indefinite NPs in Spanish. As such it aims at explaining as large a part of the data as possible and at the same time being well-defined enough for formulating precise analyses of such data. There are nevertheless, as we have seen, also cases which cannot be explained just as easily. This may be seen as the setting for the analysis presented here.

The aim of this paper was to substantiate the claim that the distinction between roles and values provides a means of explaining cases of reference which are problematic to handle in studies in the fields of linguistics and philosophy. 'Role' and 'value' are basic to the interpretation of linguistic expressions, in general, which describe entities. They apply to the level of thought in terms of the semiotic triangle, and it is the level of symbol along with context which provide information for establishing one or the other reading. By keeping these levels distinct, it is possible to show how they interact in the establishment of meaning and reference. Furthermore, due to the fact that NPs are supposed to set up both a role and a value in a mental space in an interpretive process, it is possible to explain the interpretation of linguistic expressions which do not comply with a framework which makes a static and clear-cut distinction between kinds and individuals. As a result, the advantage of applying the role/value distinction is that it cuts across, so to speak, the reading of definite and indefinite NPs. This means that it allows us to generalise over the reading of NPs in general. Moreover, the distinction between roles and values, unlike the traditional distinctions, presupposes that the role reading is basic to the value reading, as already mentioned. This provides us with a uniform basis for explaining the reading NPs in general. 
HeLle DAM-Jensen

\section{REFERENCES}

Ackrill, J. L. (1981), Aristotle the philosopher, Oxford: Oxford University Press.

Baker, C. L. (1973), Definiteness and indefiniteness in English, University og Texas at Austin: Indiana University Linguistics Club, pp. 1-23.

Coulson, Seana (2001), Semantic Leaps, Cambridge: Cambridge University Press.

Dam-Jensen, Helle (2001), A referential analysis of definite NPs in Spanish, unpublished Ph.D. thesis, Spanish Department, the Aarhus School of Business.

Donnellan, Keith (1966), "Reference and Definite Descriptions", in: Ostertag, Gary (ed.) (1998), Definite Descriptions, Cambridge, Massachusetts: Cornell University, pp. 231-244.

Dretske, Fred I. (1981), Knowledge and the Flow of Information, Oxford: Blackwell.

Dretske, Fred I. (1995), Naturalizing the Mind, Cambridge Massachusetts: The MIT Press.

Dummett, Michael (1991), Frege and other philosophers, Oxford: Clarendon Press.

Fauconnier, Gilles (1994), Mental spaces, Cambridge: Cambridge University Press.

Fauconnier, Gilles (1997), Mappings in thought and language, Cambridge: Cambridge University Press.

Fauconnier, Gilles, Mark Turner (2002), The way we think. Conceptual Blending and the Mind's Hidden Complexities, New York: Basic Books.

Fauconnier, Gilles, Mark Turner (1998), "Conceptual Integration Networks", Cognitive Science, 22/2 (1998), pp. 133-187.

Fauconnier, Gilles, Mark Turner (2000), "Compressions and global insight", Cognitive Linguistics, 11/3-4 (2000), pp. 283-304.

Fauconnnier, Gilles, Eve Sweetser (1996), “Cognitive Links and Domains: Basic Aspects of Mental Space Theory", in: Fauconnier, Gilles, Eve Sweetser (eds.) (1996), Spaces, Worlds and Grammar, Chicago/London: The University of Chicago Press, pp. 1-29.

Hawkins, John A. (1978), Definiteness and Indefiniteness, London: Croom Helm.

Kartunnen, Lauri (1976), "Discourse Referents", in: (= Syntax and Semantics, 7) McCawley, James D., (ed.) (1976), Notes from the Linguistic Underground, New York: Academic Press, pp. 262-286.

Langacker, Ronald W. (1987), Foundations of cognitive grammar, Vol. I. Theoretical Prerequisites, Stanford: Stanford University Press.

Langacker, Ronald W. (1991), Foundations of Cognitive Grammar, Vol. II. Descriptive Applications, Stanford: Stanford University Press.

Lyons, John (1977), Semantics, 2 vols., Cambridge: Cambridge University Press.

Mejías-Bikandi, Errapel (1996), "Space Accessibility and Mood in Spanish", in: Fauconnier, Gilles, Eve Sweetser (eds.) (1996), Spaces, Worlds and Grammar, Chicago/London: The University of Chicago Press, pp. 157-178. 
an Application of the Role-Value Distinction in Mental Space Theory to the Analysis of DeFINITE AND INDEFINITE NOUN PHRASES

Nurnberg, Geoffrey (1978), The Pragmatics of Reference, Bloomington, Indiana: Indiana University Linguistics Club.

Ogden, C. K., I. A. Richards (1923), The meaning of meaning, London: Routledge $\&$ Kenan Paul Ltd.

Talmy, Leonard (2000), Toward a Cognitive Semantics, 2 vols., Massachusetts: The MIT Press.

Thrane, Torben (1997), "Understanding Semantics", in: Bache, Carl, Alex Klinge (eds.) (1997), Sounds, Structures and Senses, Odense: Odense Universitetsforlag, pp. $235-250$.

Thrane, Torben (2004), "Hvorfor er sproget så svært at forstå når det er så let at forstå?", in: Engerer (red.) (2004), Volkmar, Form og betydning. Bidrag til syntaks-semantik-interface $i$ sprog og grammatik, Århus: SB-Tryk, pp. 37-70 (= Tidsskrift for Sprogforskning, 2/2 2004).

\section{NOTES}

1 It is primary substances, individuals, which are basic to the existence of everything else, not species and genera (Ackrill 1981: 120).

2 The purpose of this example is merely to illustrate Fauconnier's application of the role/value distinction as an introduction to my development of it.

3 Compare the analysis of mood in Spanish in Mejías-Bicandi (1996).

4 I am indebted to Kjær Jensen for discussion of this point. 